\title{
Estimation of failure lifetime in plywood-to-timber joints with nails and screws under cyclic loading
}

\author{
Ko Nagase $^{1} \cdot$ Kenji Kobayashi $^{2} \cdot$ Motoi Yasumura $^{2}$
}

Received: 28 November 2017 / Accepted: 30 May 2018 / Published online: 2 July 2018

(c) The Japan Wood Research Society 2018

\begin{abstract}
The performance of plywood-sheathed shear walls is determined at the plywood-to-timber joints. In joints with dowel-type fasteners, such as nails and screws, the fastener is fractured under reversed cyclic loading (e.g., seismic force), reducing the ductility of the joint. The fracture is caused by low-cycle fatigue due to the reversed cyclic bending of the fastener. Therefore, evaluating the fatigue life is important for estimating the ultimate displacement. The main objective of this study is to estimate the ultimate displacement of the joints and to enable load-displacement calculation of single shear joints under reversed cyclic displacement when bending fatigue failure of the fastener occurs. Single shear tests were conducted under different loading protocols, and the damage performances of the fasteners were determined by subjecting them to reversed cyclic bending tests. Based on the results, the failure lifetimes of joints with dowel-type fasteners were estimated. In addition, the fracture mechanism of these dowel-type fasteners was elucidated. CN50-type nails and wood screws with dimensions of $4.1 \times 38$ and $4.5 \times 50 \mathrm{~mm}$ were used as fasteners. The single shear tests showed that the smaller the displacements per cycle, the lower are the ultimate displacement and ductilities of the joints. Moreover, load-displacement relationship up to fastener failure can be approximately estimated by combining the yield model and failure lifetime.
\end{abstract}

Keywords Dowel-type fasteners $\cdot$ Cyclic loading $\cdot$ Low-cycle fatigue failure $\cdot$ Joints

\section{Introduction}

Plywood-sheathed shear walls are widely used as bearing elements against horizontal loads such as seismic forces and wind forces. To achieve the highest performance of a shear wall, it should have not only a high load-bearing capacity, but also a high ductility or ultimate deformation. Besides, the performance of a shear wall is affected by the joints between the plywood and timber. In general, the yield load of joints made with dowel-type fasteners, such as nails and screws, can be calculated based on Johansen's yield

Kenji Kobayashi

kobayashi.kenji.b@shizuoka.ac.jp

Ko Nagase

t6103003@edu.gifu-u.ac.jp

Motoi Yasumura

yasumura.motoi@shizuoka.ac.jp

1 United Graduate School of Agricultural Science, Gifu University, 836 Ohya, Suruga-ku, Shizuoka 422-8529, Japan

2 College of Agriculture, Academic Institute, Shizuoka University, 836 Ohya, Suruga-ku, Shizuoka 422-8529, Japan model [1]. Moreover, a calculation method to determine the load-displacement relationship of a single shear joint until a withdrawal or head pull-through of the fastener occurs has been proposed [2], which enables the design of joints or shear walls with enough capacity and ductility under general conditions.

However, there are cases where a joint cannot achieve enough ductility. For example, screwed joints under reversed cyclic loading such as seismic forces show fractures of the fastener [3, 4], which in turn reduces joint ductility. It is thought that heat treatment, such as tempering and quenching, decreases the ductility of the fastener. Even in nail joints, fasteners fracture under typical combinations of members and loading conditions [5-7]. The fracturing of fasteners under cyclic loading should be considered to evaluate the performances of joints or shear walls.

Fastener fractures are caused by low-cycle fatigue due to reversed cyclic bending deformation of the fastener. When a joint with a slender fastener reaches its yield state, a plastic hinge occurs at a certain position of the fastener inside the member. Reversed cyclic displacement of the joint causes similar bending deformation of the fastener at the hinge, 
consequently resulting in fracture of the fastener. Therefore, evaluating the fatigue life of a bent fastener is important for evaluating the ultimate displacement of a joint.

Low- and high-cycle fatigues are expressed as a relationship between stress, strain, energy, and number of cycles to failure [8-10]. Smith et al. [5, 6] performed single shear tests of nailed joints and three-point bending tests of nails under constant displacement and load amplitudes. They found that a fatigue life of laterally loaded nailed joints subjected to cyclic displacement or loads depends on the fatigue properties of nails and the fatigue life of joints, estimated from the fatigue data for nails in combination with Johansen's yield theory for joints with slender fasteners. Gong et al. [11] and Li et al. [12] explored and estimated the fatigue life of nailed joints in terms of damage-dissipated energy by a modified empirical energy-based criterion. They stated that the fatigue life of nailed joints could be more accurately estimated using an energy-based criterion. However, they dealt with constant loading conditions and it is difficult to estimate the ultimate displacement.

Low-cycle fatigue performance was taken into account in the design of steel structures. For example, Koyama et al. [13] estimated the failure lifetime of steel panels as energy dissipating devices by evaluating the cumulative damage according to Miner's law. They indicate that it is possible to deal with a deformation history with a combination of different amplitudes, such as seismic action. Kobayashi et al. [7] also applied Miner's law to estimate the failure lifetimes of cross-laminated timber joints with screws and laminated veneer lumber joints with nails under an ISO loading protocol, based on the damage performance of the fastener. However, no verification under various loading protocols has been carried out in joint tests. Moreover, there are only a few reports on the verification of the estimation of ultimate displacement.

The main objective of this study was to estimate the ultimate displacement of a joint when the bending fatigue failure of a fastener occurs and to enable the calculation of load-displacement relationship of single shear joints under a reversed cyclic displacement history. Constant-amplitude reversed cyclic bending tests of fasteners were conducted to evaluate the fatigue parameters of the fasteners. The load-displacement relationship and ultimate displacement of the joints were estimated from the material properties of the members and fasteners. To validate the proposed method, single shear tests under two types of loading protocols with incremental amplitudes of displacement were performed and the obtained values were compared with the estimated values.

\section{Theory}

\section{Calculation of bending angle of fastener in single shear test}

To consider the relationship between the fastener damage performance and the single shear test, the bending angle of the fastener in the single shear test should be calculated. The bending angle of a fastener $(\theta)$ in a single shear joint (Fig. 1) can be calculated according to Eq. (1). Figure 1 shows the positions of $L$ and $\delta$ in Eq. (1) at the joint

$\theta=\tan ^{-1}\left(\frac{\delta}{L}\right)$,

where $\delta$ is the displacement of the main member and the plywood in the single shear test and $L$ is the distance to the rotation center of the fastener.

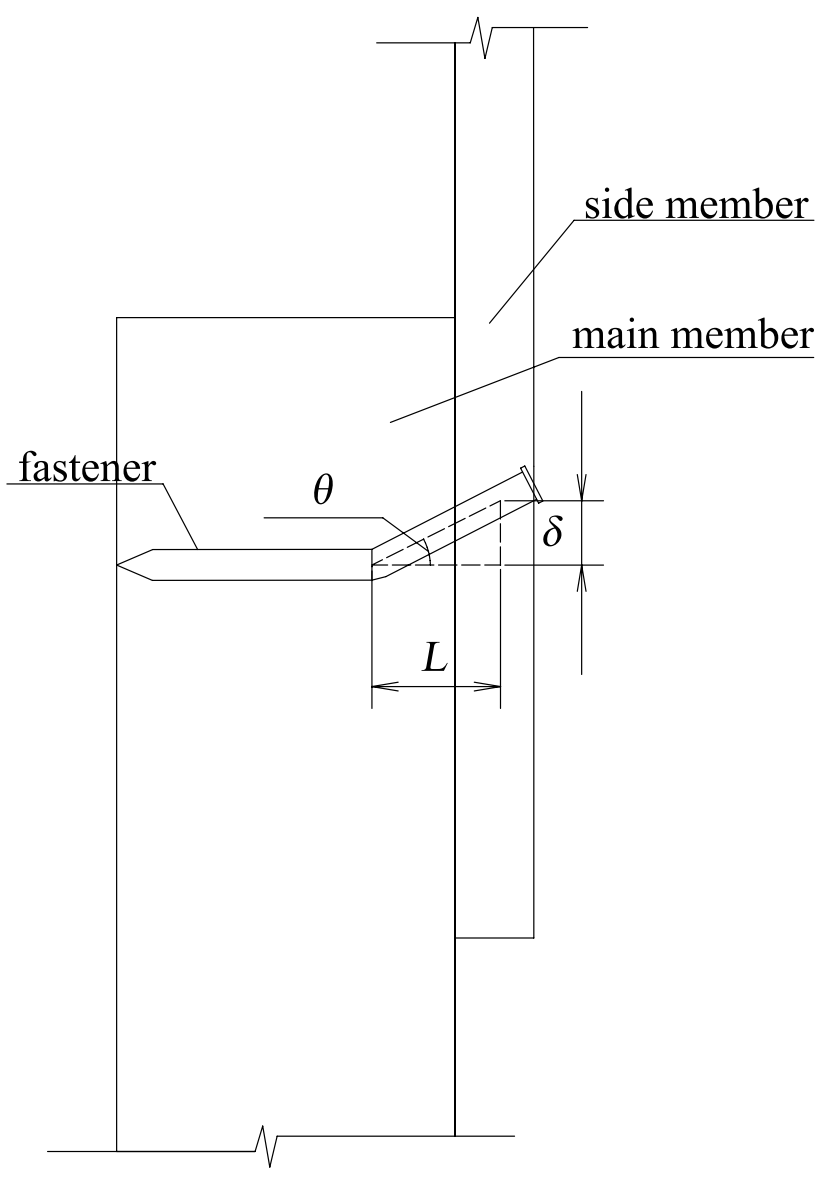

Fig. 1 Bending angle of fasteners in the single shear test. Here, $\theta$ is the bending angle of a fastener, $\delta$ isthe displacement of the main member and theplywood in the single shear test, and $L$ is thedistance to the rotation center of the fastener 


\section{Calculation of failure lifetime from Miner's rule and Manson Coffin's rule}

Fasteners fracture by low-cycle fatigue when the steel material receives a reversed cyclic load of plastic deformation. Fatigue fracture occurs with $10^{4}$ cycles or less. A low-cycle fatigue is established for many materials based on Manson Coffin's rule (Eq. 2) [8, 9]

$\frac{\Delta \epsilon_{\mathrm{p}}}{2}=\epsilon_{\mathrm{f}}^{\prime} \cdot(2 N)^{C}$,

where $\Delta \epsilon_{\mathrm{p}} / 2$ is the plastic strain amplitude, $\epsilon_{\mathrm{f}}^{\prime}$ is the fatigue ductility coefficient, $2 N$ is the number of cycles to failure, and $C$ is the fatigue ductility exponent. Here, the plastic strain $\left(\epsilon_{\mathrm{p}}\right)$ could be simply replaced by the plastic deformation angle $\left(\gamma_{\mathrm{p}}\right)$. Equation (2) is modified to Eq. (3) by replacing $\epsilon_{\mathrm{p}}$ with $\gamma_{\mathrm{p}}$ as follows:

$\frac{\Delta \gamma_{\mathrm{p}}}{2}=\gamma_{\mathrm{f}} \cdot\left(2 N_{\mathrm{f}}\right)^{C}$,

where $\gamma_{\mathrm{p}} / 2$ is the plastic deformation angle, $2 N_{\mathrm{f}}$ is the number of cycles to failure, and $\gamma_{\mathrm{f}}$ and $C$ are the regression coefficients.

Miner's rule was used to evaluate fatigue life [14], as expressed in Eq. (4). Miner's rule is an empirical rule that predicts the life up to fatigue failure when the object undergoes fluctuating stress that is not a constant waveform in material fatigue. Fatigue failure occurs when

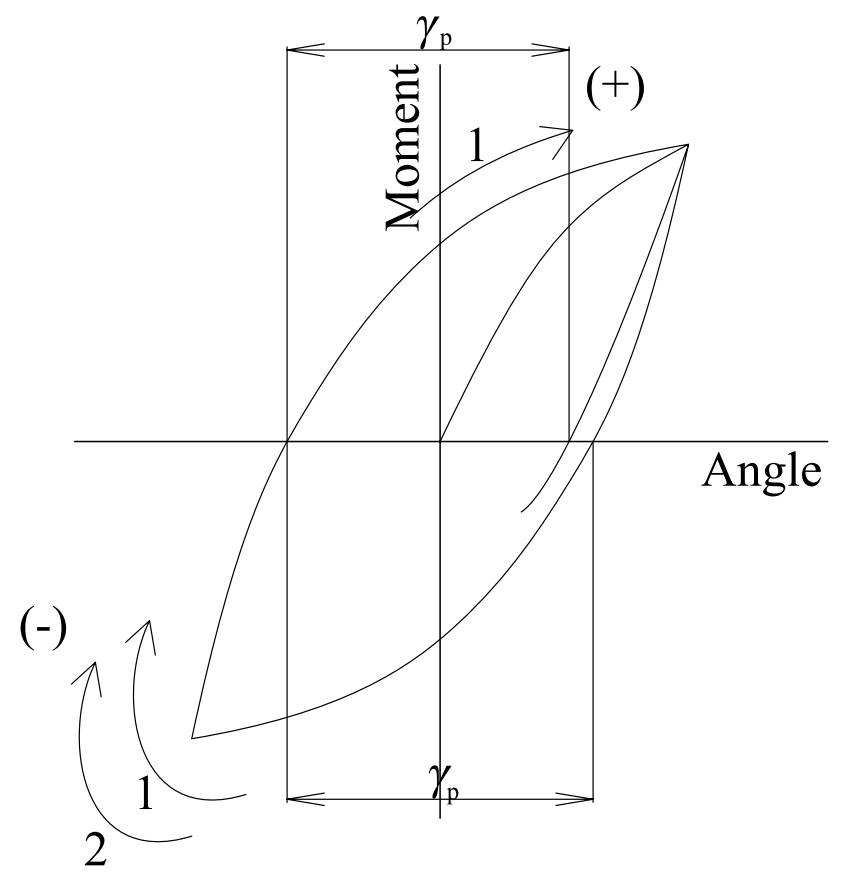

Fig. 2 Plastic deformation amplitude $\left(\gamma_{\mathrm{p}}\right)$ and count method of cycles
$D \geq 1$. In this study, the number of cycles when $D \geq 1$ is defined as "failure lifetime"

$D=\frac{n_{1}}{N_{1}}+\frac{n_{2}}{N_{2}}+\cdots+\frac{n_{i}}{N_{i}}=\sum \frac{n_{i}}{N_{i}}$

where $n_{1}, n_{2}, \ldots, n_{i}$ are the numbers of repetitions of each amplitude in the test, whereas $N_{1}, N_{2}, \ldots, N_{i}$ denote the numbers of repetitions up to failure of each amplitude, calculated using Manson Coffin's rule.

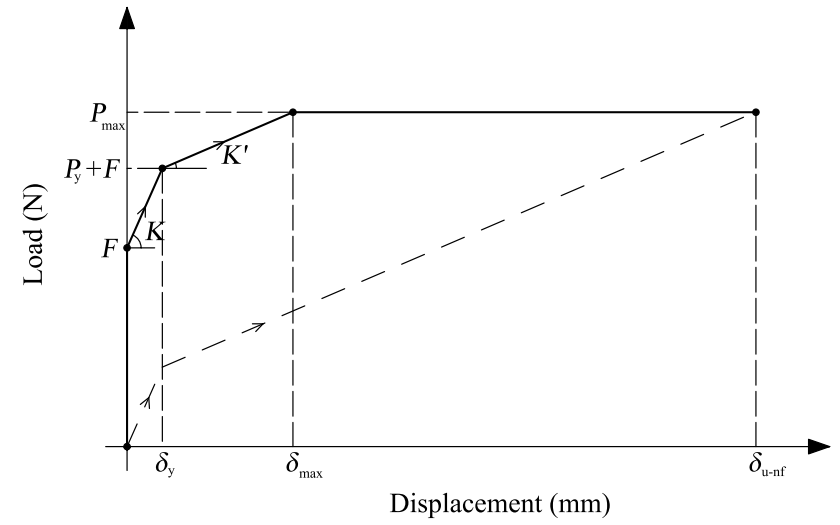

Fig. 3 Estimation curve of load-displacement relationship. Here, $F$ is the frictional force, $P_{\mathrm{y}}$ is the yield strength, $P_{\max }$ is the maximum load, $\delta_{\mathrm{y}}$ is the yield displacement, $\delta_{\max }$ is the displacement at maximum load, $\delta_{\mathrm{u}-\mathrm{nf}}$ is the ultimate displacement when the fastener does not fracture, $K$ is the initial stiffness, and $K^{\prime}$ is the secondary stiffness

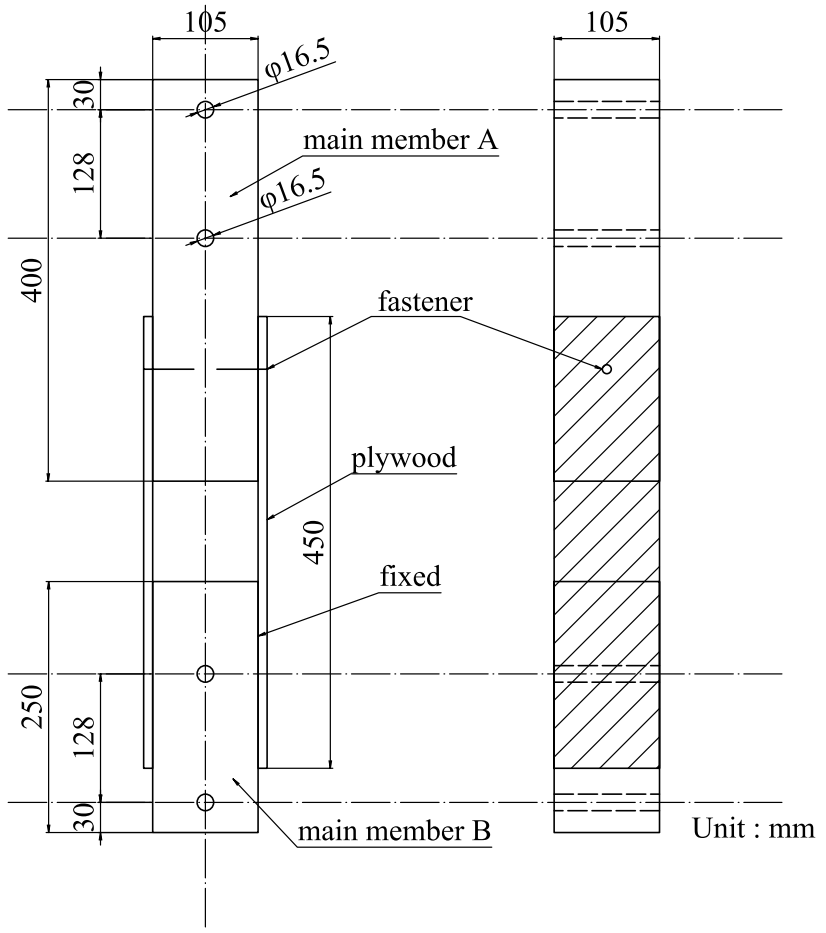

Fig. 4 Setup of single shear joints 
Table 1 Specimen series used in the single shear test

\begin{tabular}{llll}
\hline Fastener & Mono. & \multicolumn{2}{l}{ Reversed cyclic loading test } \\
\cline { 3 - 4 } & & ISO & 1 PER \\
\hline Wood screw (mm) & 6 & 6 & 6 \\
$4.1 \times 38$ & 6 & 6 & 6 \\
$4.5 \times 50$ & & & 6 \\
Nail & 6 & 6 & 6 \\
CN50 & 6 & \\
\hline
\end{tabular}

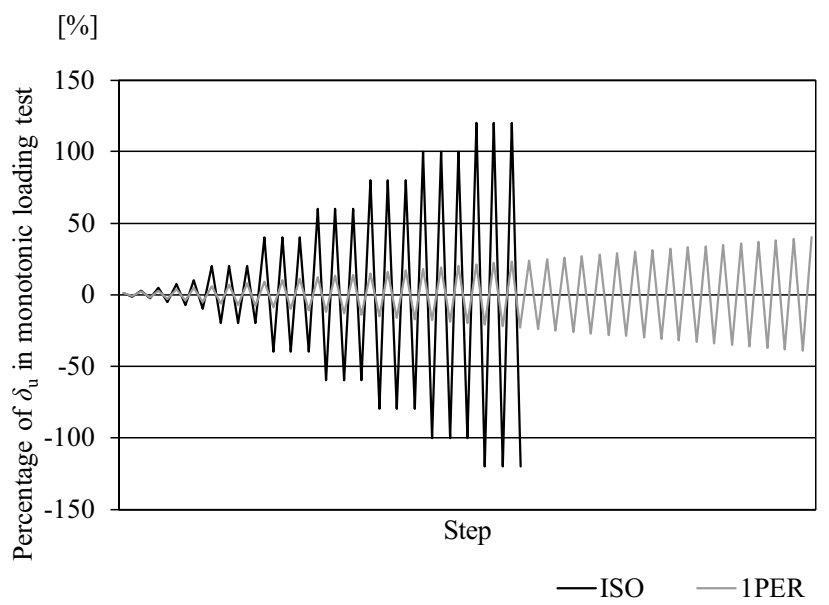

Fig. 5 Loading protocol in the single sharing test

$D \geq 1$ : fatigue failure occurs.

$D<1$ : fatigue failure does not occur.

Ultimate displacement is obtained by substituting the deformation angle corresponding to failure lifetime into Eq. (5). Equation (5) is the transformed Eq. (1) as follows:
$\delta_{\mathrm{u}-\mathrm{f}}=L \cdot \tan \gamma_{\mathrm{u}-\mathrm{f}}$,

where $\delta_{\mathrm{u}-\mathrm{f}}$ is the ultimate displacement when failure occurs by low-cycle fatigue of the fastener; and $\gamma_{\mathrm{u} \text {-f }}$ is the deformation angle corresponding to failure lifetime.

The regression coefficients of the fasteners used in Eq. (3) were obtained by the constant-amplitude reversed cyclic bending test of the fasteners. Figure 2 defines the plastic deformation amplitude $\left(\gamma_{\mathrm{p}}\right)$ and count method of cycle number $(n)$ of this study. The $\gamma_{\mathrm{p}}$ value is measured as the sum of the absolute values of the deformation angle from the interception of the hysteresis curve with the horizontal axis until its interception with the deformation axis again; $\gamma_{p}$ is excluded from the first quarter cycle. The value, $n$, is counted in positive and negative half-cycles, separately. The failure life $\left(N_{\mathrm{f}}\right)$ is determined as the average of positive and negative number of cycles up to one before the cycle in which the displacement turning point moment is less than $80 \%$ of the maximum value obtained thus far.

\section{Calculation of load-displacement relationship of joint}

According to Kobayashi et al. [15], an estimation curve of load-displacement relationship up to the maximum load can be obtained using Eqs. (6)-(17) based on the modified Johansen's yield model. Figure 3 shows the estimation curve of load-displacement relationship calculated in the following equations:

$$
\begin{aligned}
& F=\mu P_{\text {ax-ini }} \\
& P_{\text {ax-ini }}=\min \left(P_{\text {head-ini }}, P_{\text {pull }}\right)
\end{aligned}
$$
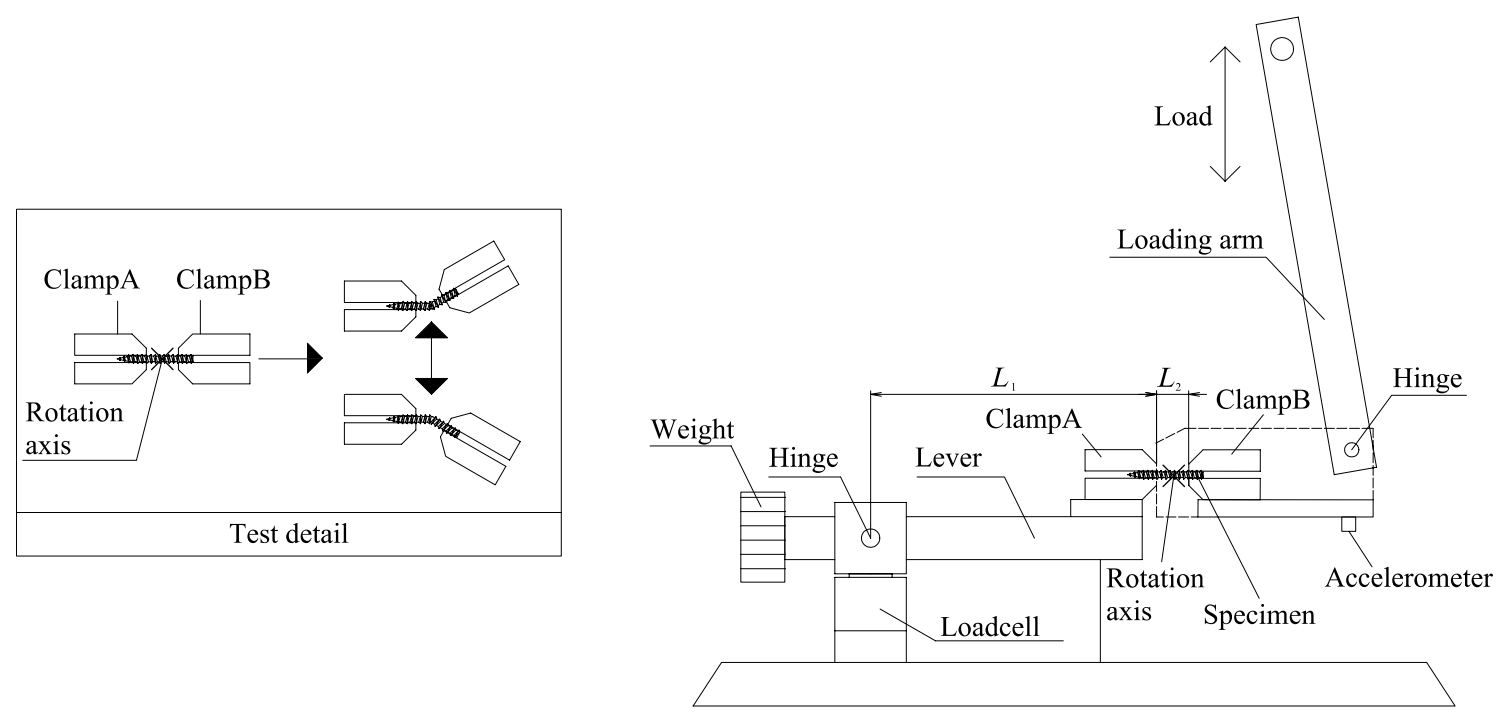

Fig. 6 Setup of constant-amplitude reversed cyclic bending test for fasteners 
$K=\frac{d k_{1} t_{1} \alpha_{\mathrm{ef}} \gamma \varphi\left(1+\alpha_{\mathrm{ef}}{ }^{3} \gamma \varphi\right)}{1+4 \alpha_{\mathrm{ef}} \gamma \varphi+6 \alpha_{\mathrm{ef}}{ }^{2} \gamma \varphi+4 \alpha_{\mathrm{ef}}{ }^{3} \gamma \varphi+\alpha_{\mathrm{ef}}{ }^{4} \gamma^{2} \varphi^{2}} \times 0.9$

$t_{\mathrm{ef} 1}=\min \left\{t_{1},\left(\frac{64 E I_{\mathrm{s}}}{k_{1} d}\right)^{\frac{1}{4}}\right\}, t_{\mathrm{ef} 2}=\min \left\{t_{2},\left(\frac{64 E I_{\mathrm{s}}}{k_{2} d}\right)^{\frac{1}{4}}\right\}$

$P_{\mathrm{y}}=\min \left\{\begin{array}{lll}\text { mode1 } & : & \mathrm{d} F_{\mathrm{e} 1} \cdot t_{1} \\ \operatorname{mode} 2 & : & \mathrm{d} F_{\mathrm{e} 1} \cdot t_{1} \alpha \beta \varphi \\ \operatorname{mode} 3: & \mathrm{d} F_{\mathrm{e} 1} \cdot \frac{\beta \varphi}{\beta \varphi+1}\left(2 L_{3}-(\alpha+1) t_{1}\right) \\ \operatorname{mode} 4: & \mathrm{d} F_{\mathrm{e} 1} \cdot \frac{\beta \varphi}{\beta \varphi+2}\left(2 L_{4}-t_{1}\right) \\ \operatorname{mode} 5: & \mathrm{d} F_{\mathrm{e} 1} \cdot \frac{\beta \varphi}{2 \beta \varphi+1}\left(2 L_{5}-\alpha t_{1}\right) \\ \operatorname{mode} 6 & : & \mathrm{d} F_{\mathrm{e} 1} \cdot \frac{\beta \varphi}{\beta \varphi+1} L_{6}\end{array}\right.$

$\left\{\begin{array}{l}L_{3}=\frac{t_{1}}{2 \beta \varphi} \sqrt{\alpha^{2} \beta^{3} \varphi^{3}+2 \beta^{2} \varphi^{2}\left(\alpha^{2}+\alpha+1\right)} \\ L_{4}=\frac{t_{1}}{2 \beta \varphi} \sqrt{\frac{4 M_{\mathrm{p}} \beta \varphi^{4}(\beta \varphi+2)}{F_{\mathrm{el}} d t_{1}^{2}}+2 \beta \varphi(\beta \varphi+1)} \\ L_{5}=\frac{t_{1}}{2 \beta \varphi} \sqrt{\frac{4 M_{\mathrm{p}} \beta \varphi(2 \beta \varphi+1)}{F_{\mathrm{el}} d t_{1}^{2}}+2 \alpha^{2} \beta^{2} \varphi^{2}(\beta \varphi+1)} \\ L_{6}=\frac{1}{\beta \varphi} \sqrt{\frac{2 M_{\mathrm{p}}\left(1+\varphi^{3}\right) \beta \varphi(\beta \varphi+1)}{F_{\mathrm{e} 1} d}}\end{array}\right.$

$\delta_{\mathrm{y}}=\frac{P_{\mathrm{y}}}{K}$

$K^{\prime}=\frac{P_{\mathrm{ax}}}{L}$

$P_{\text {ax }}=\left\{\begin{array}{l}\operatorname{mode} 3,4: \min \left\{P_{\text {head }}, P_{\text {pull }} \times C_{\text {pull }}\right\} \\ \operatorname{mode} 5,6: \min \left\{P_{\text {head }}, P_{\text {pull }}\right\}\end{array}\right.$

Table 2 Specimen series in constant-amplitude reversed cyclic bending tests of fasteners

\begin{tabular}{llrr}
\hline Fastener & \multicolumn{3}{l}{ Amplitude angle } \\
\cline { 2 - 4 } & $15^{\circ}$ & $22.5^{\circ}$ & $30^{\circ}$ \\
\hline Wood screw (mm) & 3 & 3 & \\
$4.1 \times 38$ & 4 & 10 & 3 \\
$4.5 \times 50$ & & & 10 \\
Nail & 3 & 3 & 3 \\
CN50 & & 3 & \\
\hline
\end{tabular}

$P_{\max }=\left\{\begin{array}{l}\operatorname{mode} 1,2: P_{\mathrm{y}}+F \\ \operatorname{mode} 3-6: \sqrt{P_{\mathrm{y}}^{2}+P_{\mathrm{ax}}^{2}}\end{array}\right.$

$\delta_{\max }=\left\{\begin{array}{l}\operatorname{mode} 1,2: \delta_{\mathrm{y}} \\ \operatorname{mode} 3-6: \delta_{\mathrm{y}}+\frac{\left(P_{\max }-P_{\mathrm{y}}-F\right)}{K^{\prime}}\end{array}\right.$

$$
\delta_{\mathrm{u}-\mathrm{nf}}=\left\{\begin{array}{l}
\operatorname{mode} 1,2: \delta_{\mathrm{y}} \\
\operatorname{mode} 3-6: \delta_{\mathrm{y}}+\frac{\left(P_{\max }-P_{\mathrm{y}}\right)}{K^{\prime}}
\end{array}\right.
$$

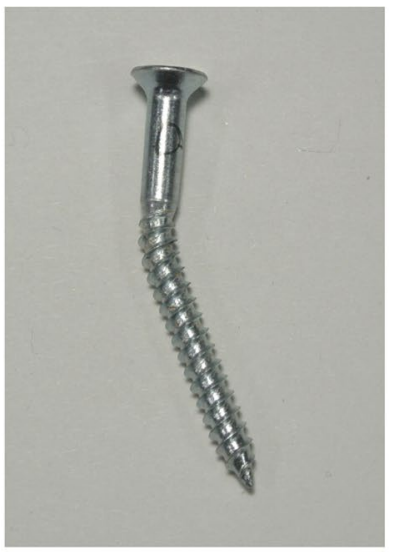

Fastener bending yield $(4.5 \times 50 \mathrm{~mm})$

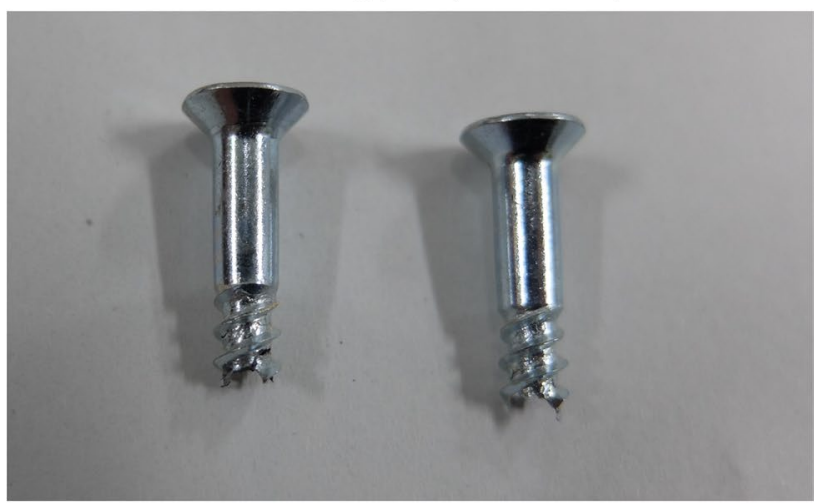

Fracture of fastener $(4.1 \times 38 \mathrm{~mm})$

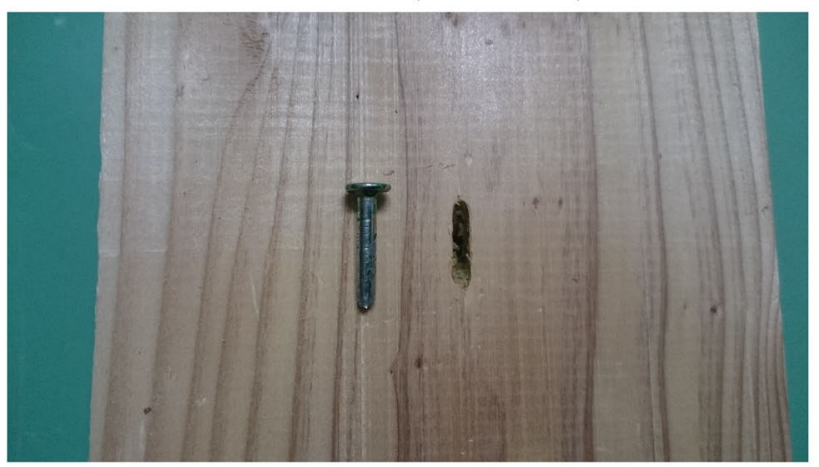

Fracture of fastener (CN50)

Fig. 7 Fracture behavior 


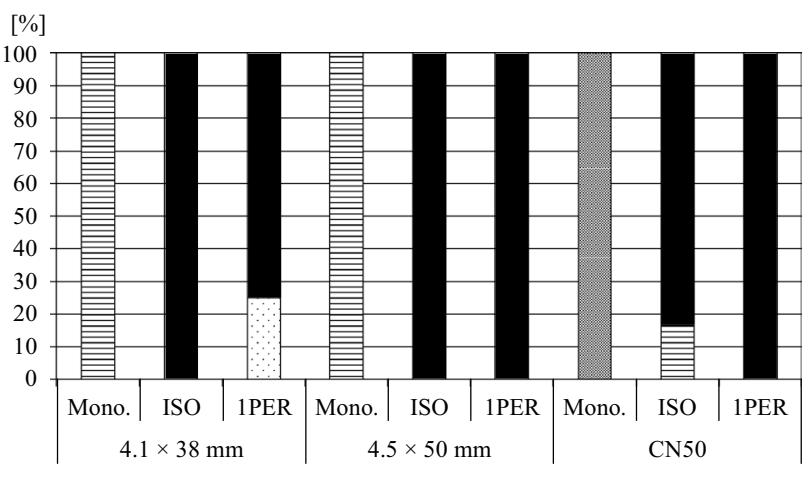

$\square$ fracture of fasteners $\boxminus$ bending yield of fastener punching out $\square$ withdraw

Fig. 8 Ratio of failure in the single shear test
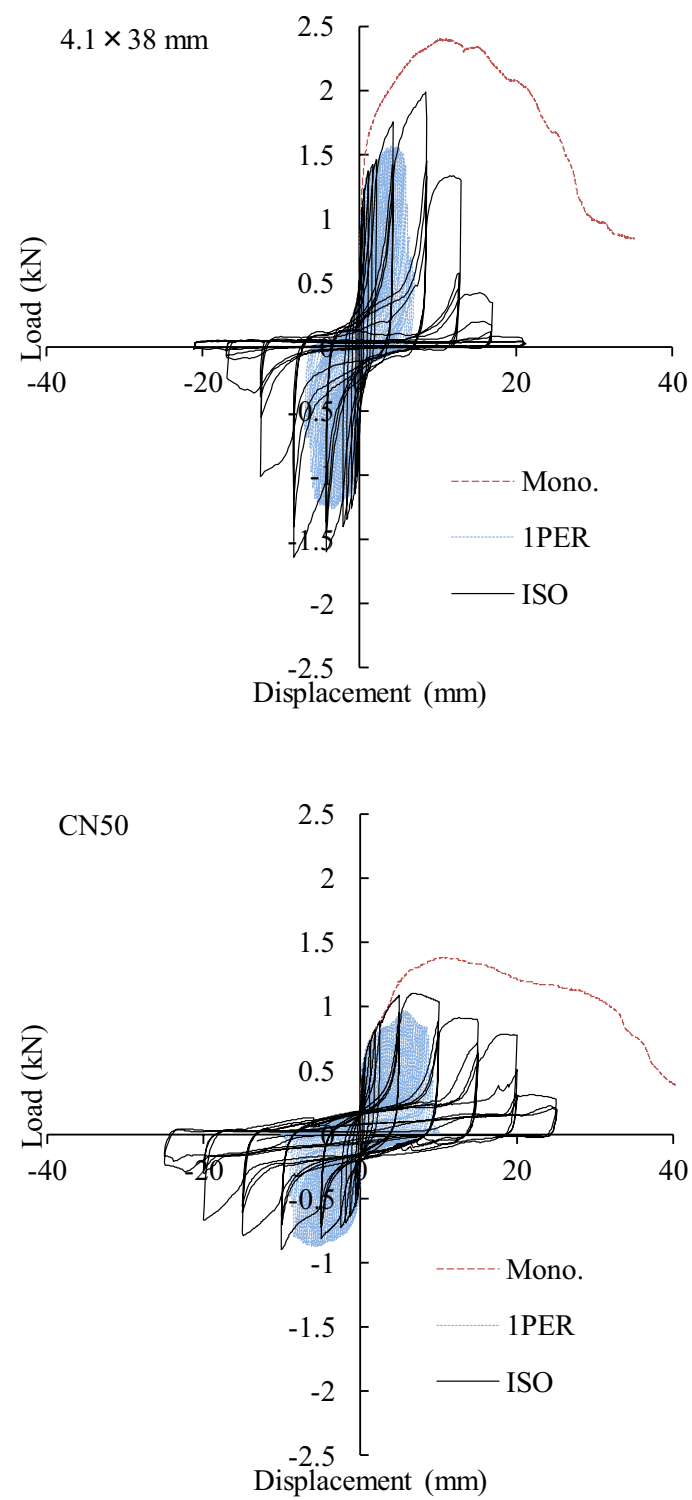

where $F$ is the frictional force $(\mathrm{N}), \mu$ is the static friction coefficient between the materials, $P_{\text {ax-ini }}$ is the initial axial force of the fastener $(\mathrm{N}), P_{\text {head-ini }}$ is the initial axial force exerted by the side member on the fastener $(\mathrm{N}), P_{\text {pull }}$ is the pull-out resistance in the main member $(\mathrm{N}), d$ is the effective diameter (root diameter or cylindrical diameter $\times 1.1)(\mathrm{mm})$, $\varphi$ is the ratio between the effective diameters $\left(=d_{2} / d_{1}\right)$, the subscript numbers 1 and 2 represent the number of the member (1: main member, 2: side member), $K$ is the initial stiffness $(\mathrm{N} / \mathrm{mm}), k$ is the embedment stiffness $\left(\mathrm{N} / \mathrm{mm}^{3}\right), t_{\text {ef }}$ is the effective rigid body length ( $\mathrm{mm}), E$ is the Young's modulus of the fastener $\left(\mathrm{N} / \mathrm{mm}^{2}\right), I_{\mathrm{s}}$ is the moment of inertia of the fastener $\left(\mathrm{mm}^{4}\right), \alpha_{\mathrm{ef}}$ is the ratio between the rigid body lengths $\left(=t_{\mathrm{ef} 2} / t_{\mathrm{ef} 1}\right), P_{\mathrm{y}}$ is the yield strength $(\mathrm{N}), L_{3}-L_{6}$ is the

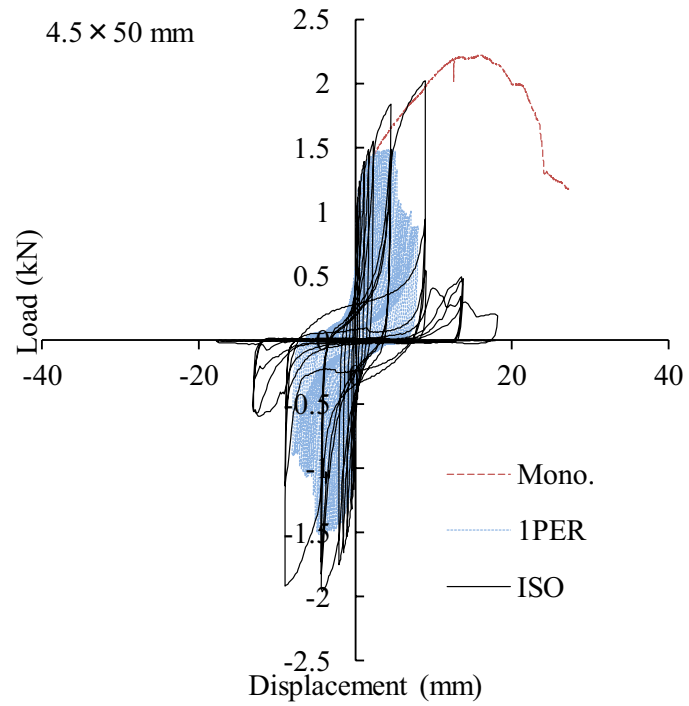

Fig. 9 Load-displacement curves 
Table 3 Characteristic results of the single shear test

\begin{tabular}{|c|c|c|c|c|c|c|c|c|c|}
\hline Specimen & $P_{\mathrm{y}}(\mathrm{kN})$ & $\delta_{\mathrm{y}}(\mathrm{mm})$ & $P_{\max }(\mathrm{kN})$ & $\delta_{\max }(\mathrm{mm})$ & $P_{\mathrm{u}}(\mathrm{kN})$ & $\delta_{\mathrm{u}}(\mathrm{mm})$ & $K(\mathrm{kN} / \mathrm{mm})$ & $\mu$ & $\Sigma E_{\mathrm{cy}}(\mathrm{kNmm})$ \\
\hline \multicolumn{10}{|c|}{$4.1 \times 38 \mathrm{~mm}$} \\
\hline Mono & $\begin{array}{c}1.22 \\
(0.24)\end{array}$ & $\begin{array}{c}0.60 \\
(0.14)\end{array}$ & $\begin{array}{c}2.12 \\
(0.42)\end{array}$ & $\begin{array}{l}11.72 \\
(3.98)\end{array}$ & $\begin{array}{c}1.92 \\
(0.37)\end{array}$ & $\begin{array}{c}21.52 \\
(2.21)\end{array}$ & $\begin{array}{c}2.16 \\
(0.74)\end{array}$ & $\begin{array}{c}24.33 \\
(7.19)\end{array}$ & $\begin{array}{l}40.26 \\
(7.91)\end{array}$ \\
\hline ISO & $\begin{array}{c}1.03 \\
(0.07)\end{array}$ & $\begin{array}{c}0.45 \\
(0.14)\end{array}$ & $\begin{array}{c}1.73 \\
(0.15)\end{array}$ & $\begin{array}{c}6.80 \\
(1.95)\end{array}$ & $\begin{array}{c}1.54 \\
(0.11)\end{array}$ & $\begin{array}{c}8.67 \\
(1.85)\end{array}$ & $\begin{array}{c}2.28 \\
(0.74)\end{array}$ & $\begin{array}{l}13.81 \\
(4.42)\end{array}$ & $\begin{array}{c}58.44 \\
(9.82)\end{array}$ \\
\hline 1PER & $\begin{array}{c}1.02 \\
(0.11)\end{array}$ & $\begin{array}{c}0.33 \\
(0.11)\end{array}$ & $\begin{array}{c}1.60 \\
(0.07)\end{array}$ & $\begin{array}{c}5.64 \\
(1.93)\end{array}$ & $\begin{array}{c}1.45 \\
(0.07)\end{array}$ & $\begin{array}{c}7.54 \\
(3.54)\end{array}$ & $\begin{array}{c}3.27 \\
(1.62)\end{array}$ & $\begin{array}{l}15.60 \\
(3.39)\end{array}$ & $\begin{array}{l}115.10 \\
(65.70)\end{array}$ \\
\hline \multicolumn{10}{|c|}{$4.5 \times 50 \mathrm{~mm}$} \\
\hline Mono & $\begin{array}{c}1.18 \\
(0.14)\end{array}$ & $\begin{array}{c}0.99 \\
(0.37)\end{array}$ & $\begin{array}{c}2.30 \\
(0.33)\end{array}$ & $\begin{array}{l}15.28 \\
(3.57)\end{array}$ & $\begin{array}{c}2.01 \\
(0.28)\end{array}$ & $\begin{array}{l}22.50 \\
(3.20)\end{array}$ & $\begin{array}{c}1.38 \\
(0.59)\end{array}$ & $\begin{array}{l}14.77 \\
(4.81)\end{array}$ & $\begin{array}{c}44.02 \\
(11.48)\end{array}$ \\
\hline ISO & $\begin{array}{c}1.22 \\
(0.09)\end{array}$ & $\begin{array}{c}0.43 \\
(0.20)\end{array}$ & $\begin{array}{c}2.09 \\
(0.21)\end{array}$ & $\begin{array}{c}6.60 \\
(2.31)\end{array}$ & $\begin{array}{c}1.85 \\
(0.17)\end{array}$ & $\begin{array}{c}8.83 \\
(1.62)\end{array}$ & $\begin{array}{c}2.87 \\
(1.23)\end{array}$ & $\begin{array}{l}15.60 \\
(5.51)\end{array}$ & $\begin{array}{c}62.07 \\
(5.16)\end{array}$ \\
\hline 1PER & $\begin{array}{c}0.98 \\
(0.06)\end{array}$ & $\begin{array}{c}0.21 \\
(0.03)\end{array}$ & $\begin{array}{c}1.54 \\
(0.24)\end{array}$ & $\begin{array}{c}4.12 \\
(0.75)\end{array}$ & $\begin{array}{c}1.42 \\
(0.19)\end{array}$ & $\begin{array}{c}5.17 \\
(1.15)\end{array}$ & $\begin{array}{c}4.84 \\
(1.50)\end{array}$ & $\begin{array}{l}17.90 \\
(5.31)\end{array}$ & $\begin{array}{c}85.04 \\
(26.21)\end{array}$ \\
\hline \multicolumn{10}{|l|}{ CN50 } \\
\hline Mono & $\begin{array}{c}0.69 \\
(0.17)\end{array}$ & $\begin{array}{c}0.42 \\
(0.24)\end{array}$ & $\begin{array}{c}1.37 \\
(0.29)\end{array}$ & $\begin{array}{c}9.49 \\
(2.06)\end{array}$ & $\begin{array}{c}1.24 \\
(0.27)\end{array}$ & $\begin{array}{l}26.87 \\
(3.50)\end{array}$ & $\begin{array}{c}1.26 \\
(1.41)\end{array}$ & $\begin{array}{c}27.21 \\
(15.37)\end{array}$ & $\begin{array}{l}32.87 \\
(6.43)\end{array}$ \\
\hline ISO & $\begin{array}{c}0.65 \\
(0.13)\end{array}$ & $\begin{array}{c}0.50 \\
(0.14)\end{array}$ & $\begin{array}{c}1.22 \\
(0.36)\end{array}$ & $\begin{array}{c}9.10 \\
(3.17)\end{array}$ & $\begin{array}{c}1.06 \\
(0.28)\end{array}$ & $\begin{array}{c}15.84 \\
(3.44)\end{array}$ & $\begin{array}{c}0.92 \\
(0.56)\end{array}$ & $\begin{array}{c}13.72 \\
(4.58)\end{array}$ & $\begin{array}{c}65.72 \\
(26.99)\end{array}$ \\
\hline 1PER & $\begin{array}{c}0.57 \\
(0.15)\end{array}$ & $\begin{array}{c}0.28 \\
(0.05)\end{array}$ & $\begin{array}{c}0.98 \\
(0.21)\end{array}$ & $\begin{array}{c}5.26 \\
(0.68)\end{array}$ & $\begin{array}{c}0.88 \\
(0.20)\end{array}$ & $\begin{array}{c}8.27 \\
(1.74)\end{array}$ & $\begin{array}{c}1.19 \\
(0.55)\end{array}$ & $\begin{array}{l}10.93 \\
(2.04)\end{array}$ & $\begin{array}{c}97.15 \\
(33.21)\end{array}$ \\
\hline
\end{tabular}

Values in parentheses are standard deviations

$P_{\mathrm{y}}$ is the yield load, $\delta_{\mathrm{y}}$ is the yield displacement, $P_{\max }$ is the maximum load, $\delta_{\max }$ is the displacement at maximum load, $P_{\mathrm{u}}$ is ultimate load, $\delta_{\mathrm{u}}$ is the ultimate displacement, $K$ is the initial stiffness, $\mu$ is ductility factor, and $\Sigma E_{\text {cy }}$ is the total energy dissipated

distance to the rotation center of the fastener corresponding to each yield mode $(\mathrm{mm}), t$ is the thickness of the member $(\mathrm{mm}), \alpha$ is the ratio between the member thicknesses $\left(=\mathrm{t}_{2} /\right.$ $\left.\mathrm{t}_{1}\right), F_{\mathrm{e}}$ is the embedment strength $\left(\mathrm{N} / \mathrm{mm}^{2}\right), \beta$ is the ratio between the embedment strengths $\left(=F_{\mathrm{e} 2} / F_{\mathrm{e} 1}\right), M_{\mathrm{p}}$ is the bending capacity of the fastener $\left(=F_{\mathrm{t}} d^{3} / 6 \mathrm{Nmm}\right), F_{\mathrm{t}}$ is the tensile strength of fastener $(\mathrm{mm}), \delta_{\mathrm{y}}$ is the yield displacement (mm), $P_{\alpha x}$ is the axial force acting on the fastener $(\mathrm{N})$, $P_{\text {head }}$ is the penetration resistance of the side member $(\mathrm{N})$, $K^{\prime}$ is the secondary stiffness $(\mathrm{N} / \mathrm{mm}), P_{\text {max }}$ is the maximum load $(\mathrm{N}), \delta_{\text {max }}$ is the displacement at maximum load, $C_{\text {pull }}$ is reduction coefficient (assumed to 0.75), and $\delta_{\mathrm{u}-\mathrm{nf}}$ is the ultimate displacement when the fastener does not fracture $(\mathrm{mm})$.

According to this model, there are six yield modes. The bending yield of the fastener occurs in three modes among these (modes 4-6) and the fracture of the fastener should be considered. The distance to the center of rotation $L$ in Eq. (1) can be calculated using Eq. (11). The ultimate displacement is obtained by Eq. (18), as the minimum value of Eqs. (5) and (11)

$\delta_{\mathrm{u}}=\left\{\begin{array}{l}\operatorname{mode} 1-3: \delta_{\mathrm{u}-\mathrm{nf}} \\ \operatorname{mode} 4-6: \min \left(\delta_{\mathrm{u}-\mathrm{f}}, \delta_{\mathrm{u}-\mathrm{nf}}\right)\end{array}\right.$,

where $\delta_{\mathrm{u}}$ is the ultimate displacement of a joint.

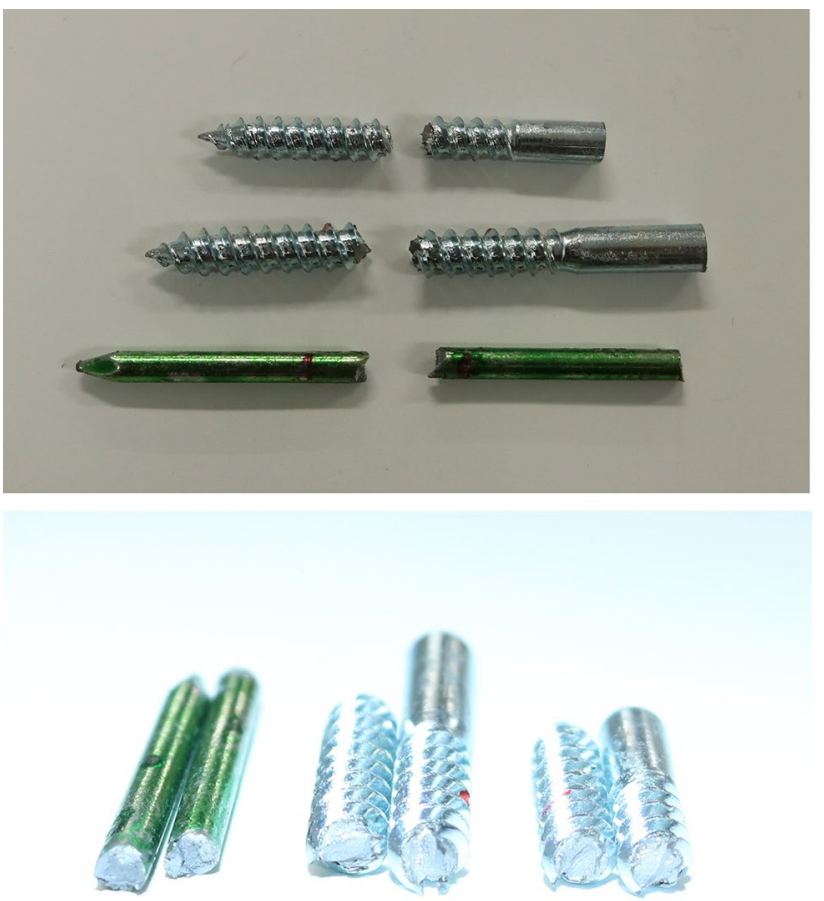

Fig. 10 Fractured fasteners (from the top: $4.1 \times 38 \mathrm{~mm}, 4.5 \times 50 \mathrm{~mm}$, and CN50) 
$4.1 \times 38 \mathrm{~mm}$

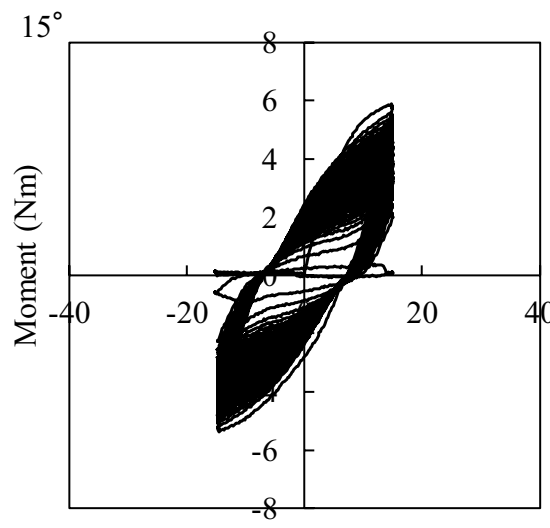

Deformation angle (deg.)

$4.5 \times 50 \mathrm{~mm}$

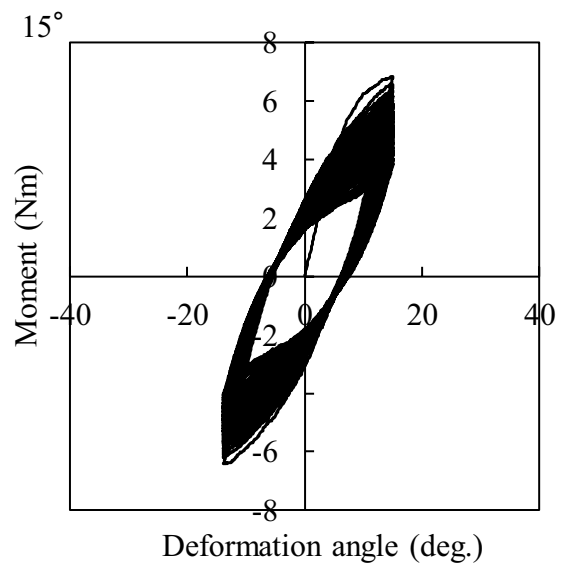

CN50

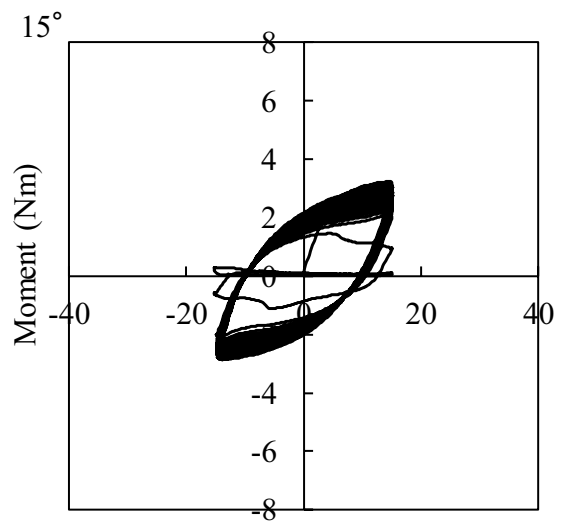

Deformation angle (deg.)

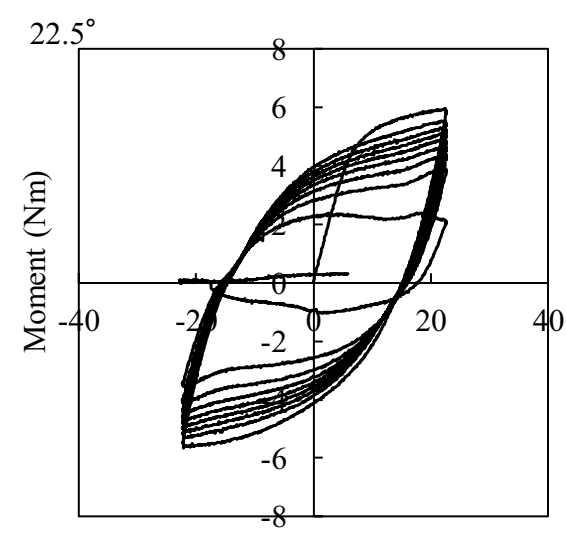

Deformation angle (deg.)

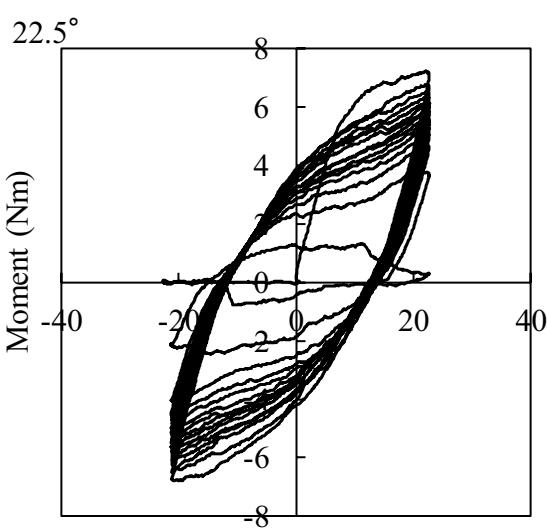

Deformation angle (deg.)

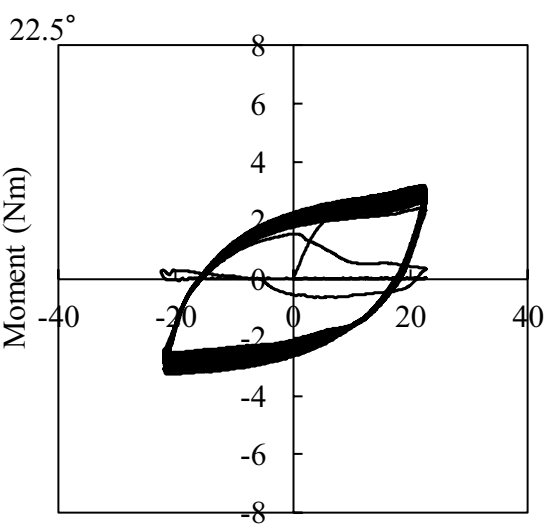

Deformation angle (deg.)

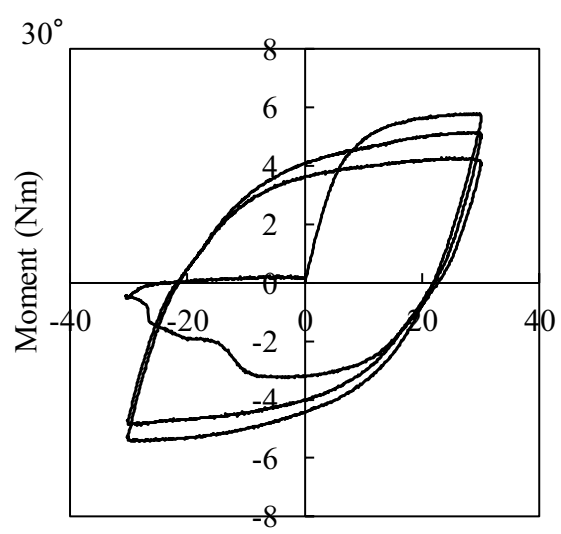

Deformation angle (deg.)
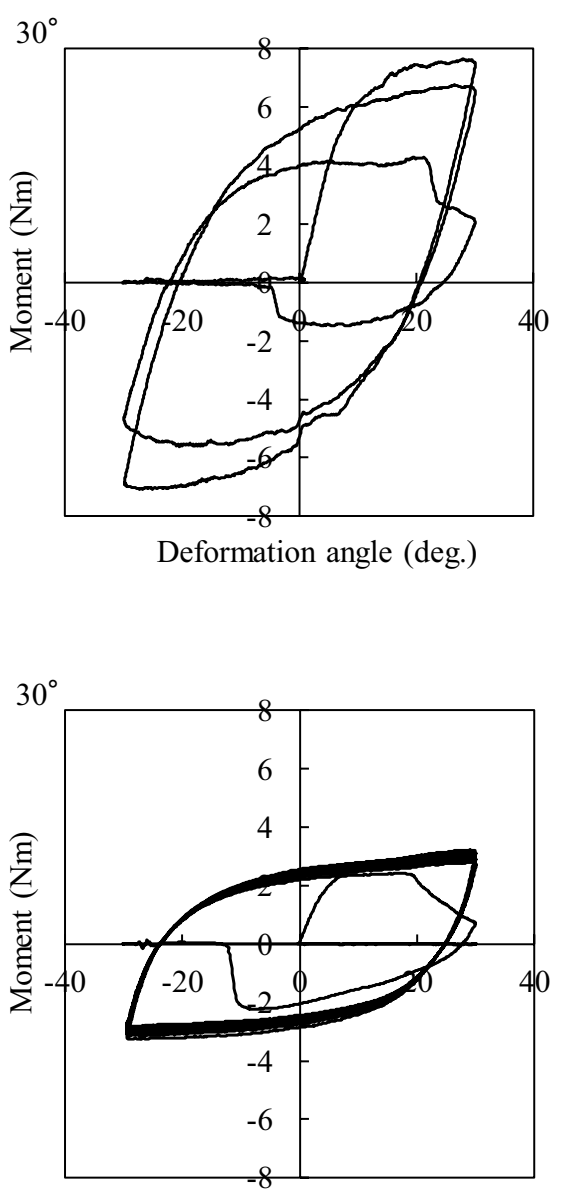

Deformation angle (deg.)

Fig. 11 Moment-deformation angle curve 


\section{Materials and methods}

\section{Single shear test of joint}

Single shear joints are set up as shown in Fig. 4. Japanese cedar (Cryptomeria japonica, density $407 \mathrm{~kg} / \mathrm{m}^{3}$ ) and softwood plywood (thickness $9.0 \mathrm{~mm}$, density $536 \mathrm{~kg} / \mathrm{m}^{3}$ ) were used as the main and side members, respectively, and nails (CN50 (diameter $=2.87 \mathrm{~mm}$ ), according to Japanese Industrial Standard (JIS) A5508 [16]) and wood screws (dimensions $=4.1 \times 38$ and $4.5 \times 50 \mathrm{~mm}$; JIS B1112 [17]) were used as fasteners. The main member A and each side member were connected using one fastener and the fixed main member B and each side member were connected with five or more screws.

Each main member was connected to a universal test machine (Shimadzu Autograph AG-I). The applied load was measured using an electronic load cell (capacity $=50 \mathrm{kN}$ ), and the relative displacements between the main member and the different side members were measured with electronic transducers (capacity $=100 \mathrm{~mm}$, Tokyo Sokki Kenkyujo SDP-100C).

The specimen series are shown in Table 1. Both monotonic and reversed cyclic loading tests were conducted. Two loading protocols were used for the reversed cyclic loading test, as shown in Fig. 5. The first was determined according to ISO 16670 [18], hereinafter referred to as "ISO." The second protocol involved gradually increasing the displacement by $1 \%$ of the ultimate displacement $\left(\delta_{u}\right)$ during the monotonic loading test, hereinafter referred to as "1PER." In ISO, the amount of displacement per cycle is large; thus, the estimation of ultimate displacement is relatively simple. 1PER was set to verify the estimation of ultimate displacement in detail by gradually increasing the displacement over that of ISO.

\section{Constant-amplitude reversed cyclic bending test for fasteners}

The setup of the constant-amplitude reversed cyclic bending test for the fasteners is shown in Fig. 6. The fasteners were the same as those used in the single sharing test. The specimen series are shown in Table 2. The loads were applied using the universal test machine. In the test, the arm was moved up and down. Clamp B, which was connected to the rotation axis and the loading arm, applied bending moments to the specimen. The load was measured using a load cell installed at the position shown in Fig. 6. The deformation angle was calculated from the following equation:

$\theta=\sin ^{-1}\left(\frac{a}{g}\right)$ where $a$ is the acceleration $\left(\mathrm{m} / \mathrm{s}^{2}\right)$ measured using an accelerometer, and $g$ is the gravitational acceleration $(=9.80665 \mathrm{~m} /$ $\mathrm{s}^{2}$ ). The constant-amplitude reversed cycle loading protocol was $\pm 15^{\circ}, \pm 22.5^{\circ}$, and $\pm 30^{\circ}$ until fracture. The span

Table 4 Characteristic results of the constant-amplitude reversed cyclic bending test

\begin{tabular}{|c|c|c|c|c|c|}
\hline Specimen & $\begin{array}{l}M_{\max } \\
(\mathrm{Nm})\end{array}$ & $\begin{array}{l}\gamma_{\mathrm{p}} \\
\text { (deg.) }\end{array}$ & $N_{\mathrm{f}}$ & $\begin{array}{l}\Sigma E_{\mathrm{cy}} \\
(\mathrm{Nm})\end{array}$ & $\begin{array}{l}E_{\text {cy-ave }} \\
(\mathrm{Nm})\end{array}$ \\
\hline \multicolumn{6}{|c|}{$4.1 \times 38 \mathrm{~mm}$} \\
\hline $15^{\circ}$ & $\begin{array}{c}5.59 \\
(0.05)\end{array}$ & $\begin{array}{l}14.61 \\
(0.40)\end{array}$ & $\begin{array}{l}12.67 \\
(0.76)\end{array}$ & $\begin{array}{l}22.70 \\
(1.94)\end{array}$ & $\begin{array}{c}0.90 \\
(0.06)\end{array}$ \\
\hline $22.5^{\circ}$ & $\begin{array}{c}5.78 \\
(0.05)\end{array}$ & $\begin{array}{l}27.87 \\
(1.74)\end{array}$ & $\begin{array}{c}6.00 \\
(1.73)\end{array}$ & $\begin{array}{l}21.77 \\
(4.40)\end{array}$ & $\begin{array}{c}1.84 \\
(0.19)\end{array}$ \\
\hline $30^{\circ}$ & $\begin{array}{c}5.70 \\
(0.10)\end{array}$ & $\begin{array}{l}42.78 \\
(1.13)\end{array}$ & $\begin{array}{c}2.00 \\
(0.00)\end{array}$ & $\begin{array}{l}11.74 \\
(0.21)\end{array}$ & $\begin{array}{c}2.93 \\
(0.05)\end{array}$ \\
\hline \multicolumn{6}{|c|}{$4.5 \times 50 \mathrm{~mm}$} \\
\hline $15^{\circ}$ & $\begin{array}{c}6.68 \\
(0.19)\end{array}$ & $\begin{array}{l}11.84 \\
(1.11)\end{array}$ & $\begin{array}{l}14.50 \\
(3.19)\end{array}$ & $\begin{array}{l}25.17 \\
(3.49)\end{array}$ & $\begin{array}{c}0.89 \\
(0.13)\end{array}$ \\
\hline $22.5^{\circ}$ & $\begin{array}{c}7.17 \\
(0.10)\end{array}$ & $\begin{array}{l}25.92 \\
(0.80)\end{array}$ & $\begin{array}{c}5.25 \\
(0.82)\end{array}$ & $\begin{array}{l}22.46 \\
(2.61)\end{array}$ & $\begin{array}{c}2.15 \\
(0.09)\end{array}$ \\
\hline $30^{\circ}$ & $\begin{array}{c}7.23 \\
(0.11)\end{array}$ & $\begin{array}{l}41.38 \\
(0.98)\end{array}$ & $\begin{array}{c}1.70 \\
(0.35)\end{array}$ & $\begin{array}{l}12.13 \\
(2.59)\end{array}$ & $\begin{array}{c}3.56 \\
(0.08)\end{array}$ \\
\hline \multicolumn{6}{|l|}{ CN50 } \\
\hline $15^{\circ}$ & $\begin{array}{c}3.02 \\
(0.06)\end{array}$ & $\begin{array}{l}19.79 \\
(0.35)\end{array}$ & $\begin{array}{c}64.83 \\
(22.68)\end{array}$ & $\begin{array}{c}89.42 \\
(30.82)\end{array}$ & $\begin{array}{c}0.69 \\
(0.02)\end{array}$ \\
\hline $22.5^{\circ}$ & $\begin{array}{c}3.16 \\
(0.12)\end{array}$ & $\begin{array}{l}33.65 \\
(0.16)\end{array}$ & $\begin{array}{l}25.67 \\
(5.58)\end{array}$ & $\begin{array}{c}66.52 \\
(12.48)\end{array}$ & $\begin{array}{c}1.30 \\
(0.04)\end{array}$ \\
\hline $30^{\circ}$ & $\begin{array}{c}3.24 \\
(0.06)\end{array}$ & $\begin{array}{l}47.61 \\
(0.82)\end{array}$ & $\begin{array}{l}11.17 \\
(1.26)\end{array}$ & $\begin{array}{l}44.07 \\
(3.48)\end{array}$ & $\begin{array}{c}1.98 \\
(0.07)\end{array}$ \\
\hline
\end{tabular}

Values in parentheses are standard deviations

$M_{\max }$ is the maximum bending moment, $\gamma_{\mathrm{p}}$ is the plastic deformation angle, $N_{\mathrm{f}}$ is the number of cycles to failure, $\Sigma E_{\mathrm{cy}}$ is the total energy dissipated, and $E_{\text {cy-ave }}$ is the average of energy dissipated

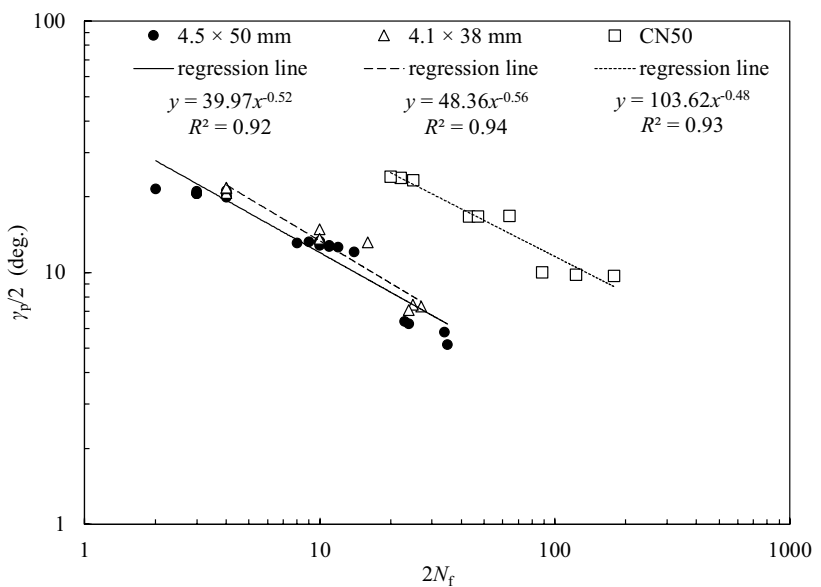

Fig. 12 Relationship between plastic deformation angle and number of cycles to failure 
$\left(L_{2}\right)$ was twice the diameter of the connector. The bending moment at the fastener was calculated from the following equation:

$M=\left(L_{1}+L_{2}\right) P$,

where $M$ is the bending moment at the fastener (Nmm), $L_{1}$ is the horizontal distance between the load cell and the tip of Clamp A (mm), $L_{2}$ is the distance between Clamps A and B (mm), and $P$ is the load measured by the load cell $(\mathrm{N})$.

\section{Results and discussion}

\section{Single shear test}

The fracture behavior is shown in Fig. 7, and the failure ratio in the single shear test is shown in Fig. 8. In the monotonic loading test, after the fastener yields, punching out was observed for the CN50 nail specimen, and bending yield was observed for both the wood screw specimens. In addition, $17 \%$ of the ISO CN50 nail specimens showed withdrawal, whereas $83 \%$ showed fastener fracture. All the 1PER specimens of CN50 type failed via fastener fracture. Fastener fracture was observed for all specimens (both ISO and 1PER) with dimensions of $4.5 \times 50 \mathrm{~mm}$. For the specimens with dimensions of $4.1 \times 38 \mathrm{~mm}$, fastener fracture was observed in the ISO specimen. Moreover, fastener fracture was observed in $75 \%$ of the 1PER specimens, and withdrawal was observed in the rest. In the 1PER specimens showing withdrawal, the yield occurred in mode 3 (embedment to main member and side member), and the fastener was rotated out.

The load-displacement curves are shown in Fig. 9. To compare each test series, the characteristic values obtained in the single shear test are shown in Table 3. For both nails and screws, $\delta_{\mathrm{u}}$ was maximum for the monotonic specimen and minimum for the 1PER specimen. The results indicate that ductility was reduced owing to fastener fracture under reversed cyclic load. During the reversed cyclic loading tests (ISO, 1PER), the $\delta_{\mathrm{u}}$ of the nail joints were higher than that of the screw joints. Therefore, the decrease in ductility of the nail specimens was smaller than the decrease in ductility of the wood screw specimens. In nail specimens, the total energy dissipated, $\Sigma E_{\text {cy }}$, tended to decrease as the amount of displacement per cycle increased. On the other hand, in wood screw specimens, $\Sigma E_{\text {cy }}$ was the smallest for the $15^{\circ}$ specimen, and there was no significant difference in $\Sigma E_{\text {cy }}$ of the $22.5^{\circ}$ specimen and the $30^{\circ}$ specimen.

\section{Constant-amplitude reversed cyclic bending test of fasteners}

The fractured fasteners are shown in Fig. 10. The fracture behaviors are similar, regardless of $\gamma_{p}$. Crack propagation was observed at the compression/tension side of the section, and the final fracture was observed at the center of the section. The moment-deformation angle curves obtained by the constant-amplitude reversed cyclic bending test of the fasteners are shown in Fig. 11, and the characteristic results are shown in Table 4 . The $N_{\mathrm{f}}$ value tended to increase with decreasing $\gamma_{\mathrm{p}}$ for all the examined specimens. In this test, to confirm whether Manson Coffin's rule was established, the relationship between $\gamma_{\mathrm{p}}$ and $2 N_{\mathrm{f}}$ is shown in Fig. 12. In all the specimens, the logarithmic relationship between $\gamma_{\mathrm{p}}$ and $N_{\mathrm{f}}$ is linear. The nail specimens tended to have higher $N_{\mathrm{f}}$ and higher ductilities than those of the wood screws. Moreover, for the wood screws, there was no significant difference in length and diameter. In all specimens, the larger the displacement per cycle, the larger is the energy dissipated per cycle, i.e., $E_{\text {cy-ave }}$.
Table 5 Failure lifetime estimation results

\begin{tabular}{lllll}
\hline & $\begin{array}{l}\text { Predicted fail- } \\
\text { ure lifetime }\end{array}$ & $\begin{array}{l}\text { Average of experi- } \\
\text { ment failure lifetime }\end{array}$ & $\begin{array}{l}\text { Displacement at pre- } \\
\text { dicted failure lifetime } \\
(\mathrm{mm})\end{array}$ & $\begin{array}{l}\text { Averages of experi- } \\
\text { mental values }\left(\delta_{\mathrm{u}}\right) \\
(\mathrm{mm})\end{array}$ \\
\hline ISO & & & & \\
$4.1 \times 38 \mathrm{~mm}$ & 21 & $20.7(2.0)$ & 8.46 & $8.67(1.85)$ \\
$4.5 \times 50 \mathrm{~mm}$ & 20 & $18.5(0.5)$ & 8.89 & $8.89(1.62)$ \\
$\mathrm{CN} 50$ & 25 & $24.0(4.0)$ & 16.12 & $16.12(3.77)$ \\
$1 \mathrm{PER}$ & & & & $5.72(0.96)$ \\
$4.1 \times 38 \mathrm{~mm}$ & 53 & $52.3(7.8)$ & 5.71 & $5.17(1.15)$ \\
$4.5 \times 50 \mathrm{~mm}$ & 58 & $45.2(10.2)$ & 5.93 & $8.27(1.74)$ \\
$\mathrm{CN} 50$ & 60 & $64.8(15.2)$ & 8.06 & \\
\hline
\end{tabular}

Values in parentheses are standard deviations 


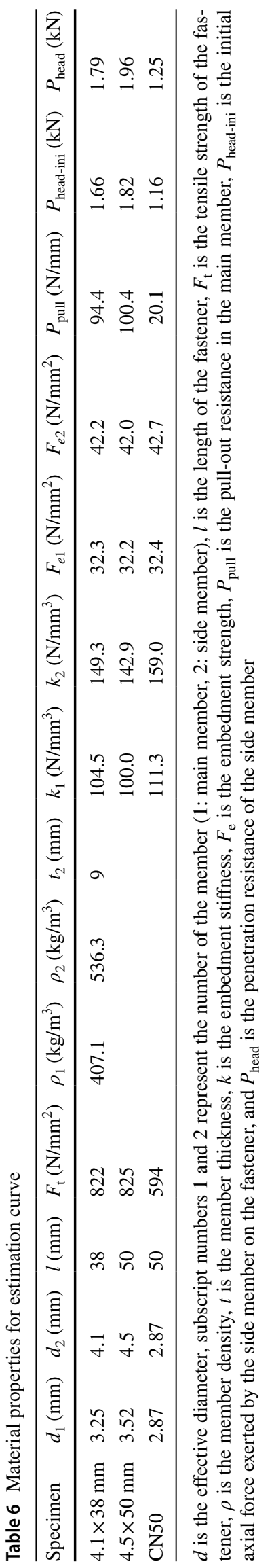

\section{Estimation of failure lifetime of single shear test from the constant-amplitude reversed cyclic bending test of fasteners}

The fatigue life was evaluated based on the results of the constant-amplitude reversed cyclic bending test of the fasteners. The estimation results are shown in Table 5 . The failure lifetime of the single shear test was theoretically estimated. The experimental values of the evaluation results are applicable only for the test specimens in which either fastener fracture or flexural yielding was observed. The failure lifetimes can be estimated for all the specimens under both the ISO and 1PER test conditions. The bending-yield-type joint subjected to reversed cyclic loading fractured because of the low-cycle fatigue of the fastener. The material properties for the estimation curve are shown in Table 6, and the experimental and estimated envelope curves are shown in Fig. 13. The estimated envelope curves and failure displacements were calculated from Eqs. (6)-(18). The estimated curves were found to be fairly accurate. Therefore, the bending angle calculated from Johansen's yield model was inferred to be consistent with the estimated result. It was confirmed that by evaluating the fatigue life of the fastener, one could estimate the influence of the loading protocol on the joint.

\section{Conclusions}

In this study, the failure lifetime of a single shear test was estimated by conducting constant-amplitude reversed cycling bending tests of a fastener for the fracture of a bending-yield-type joint. The following conclusions were drawn based on the obtained results. In the single shear test, the smaller the displacement per cycle, the lower is the ultimate displacement and ductility. It was found that the failure lifetime of the single shear test could be estimated by calculating the bending angle based on Johansen's yield model and by evaluating the failure lifetime of the fastener under bending deformation by Miner's rule. In the single shear tests, failure lifetime could not be estimated by this method when breakage other than fastener fracture and bending yield was observed. The estimation curve obtained using Johansen's yield model were used to estimate the experimental result with good accuracy. By combining this with the method of estimating the failure lifetime described herein, the load-displacement relationship up to failure can be expressed. 


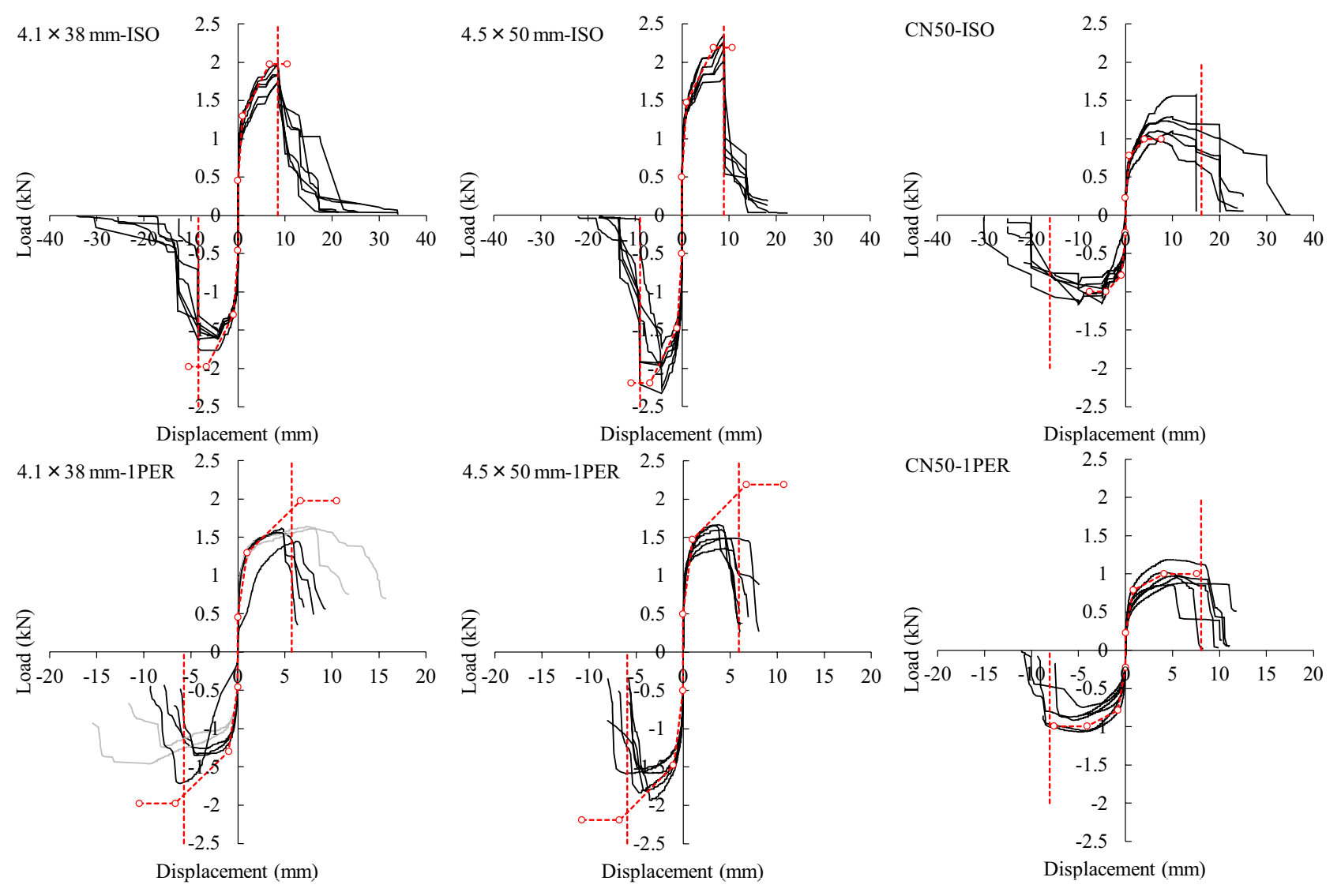

- Envelope curve (fastener fracture)

Envelope curve (withdrawal failure)

-----Estimated failure displacement

--๑--Estimated curve

Fig. 13 Experimental and estimated envelop curves

Acknowledgements This work was supported by JSPS KAKENHI Grant number 15K18721.

\section{References}

1. Johansen KW (1949) Theory of timber connections. Publication No. 9. IABSE, Bern, Switzerland, pp 249-262

2. Kobayashi K, Inayama M, Ando N (2007) New estimation method on stiffness and strength of single-shear screw joints with structural panels (In Japanese). J Struct Constr Eng Trans AIJ 72:121-128

3. Kawasaki M, Nanami N, Yasumura M (2008) Estimating single shear capacity of screwed timber joints by yield theory (In Japanese). J Struct Constr Eng Trans AIJ 73:1797-1804

4. Kobayashi K, Yasumura M (2011) Evaluation of plywood sheathed shear walls with screwed joints tested according to ISO 21581. Proceedings of 44th CIB-W18 meeting, 44-15-8, Alghero, Italy, 29 Aug-1 Sep 2011

5. Smith I, Gong M, Foliente G (2002) Predicting cyclic fatigue behaviour of laterally loaded nailed timber joints. Proceedings of the 7th WCTE, Shah Alam, Selangor, Malaysia, 12-15 Aug 2002, pp 2472-2478

6. Smith I, Gong M, Foliente G (2003) Fatigue behaviour of laterally loaded nailed timber joints. Proceedings of the ICFP, Daejeon, Korea, 21-24 Apr 2003, pp 63-71
7. Kobayashi K, Yasumura M, Hayashi K (2017) Cyclic bending fatigue properties of dowel type fasteners. Proceedings of 4 th INTER, 50-7-4, Kyoto, Japan, 28-31 Aug 2017, pp 111-123

8. Manson SS (1953) Behavior of materials under conditions of thermal stress. NACA TN-2933. National Advisory Committee for Aeronautics, Washington DC

9. Coffin LF (1954) A study of the effects of cyclic thermal stresses on a ductile metal. Trans ASME 76:931-950

10. Li DM, Nam WJ, Lee CS (1998) A strain energy-based approach to the low-cycle fatigue damage mechanism in a high-strength spring steel. Metall Mater Trans A 29:1431-1440

11. Gong M, Li L, Smith I (2008) Waveform effect on fatigue behavior of laterally loaded nailed timber joints. Proceedings of 10th WCTE, Miyazaki, Japan, 2-5 Jun 2008

12. Li L, Gong M, Smith I, Li D (2012) Exploratory study on fatigue behaviour of laterally loaded, nailed timber joints, based on a dissipated energy criterion. Holzforschung 66:863-869

13. Koyama M, Aoki H (2002) Study on the parameter of evaluating cumulative damage of alternative deformed steel members: proposal of the method of evaluation of cumulative damage and its practical application: depending on constant amplitude alternative loading experiments of damage concentrated anti-seismic members using ultra low yield point steel (in Japanese). J Struct Constr Eng Trans AIJ 67:159-166

14. Miner MA (1945) Cumulative damage in fatigue. J Appl Mech Trans ASM 67:159-164 
15. Kobayashi K, Yasumura M (2014) Shear properties of timberto-timber joints with large size self-tapping screws. 13th WCTE, Session 2.7, ABS656, Quebec, Canada, 10-14 Aug 2014

16. JIS A 5508-2009 (2009) Nails (In Japanese). Japanese Standards Association, Tokyo
17. JIS B 1112-1995 (1995) Cross-recessed head wood screws (In Japanese). Japanese Standards Association, Tokyo

18. ISO 16670 (2003) Timber structures-joints made with mechanical fasteners-Quasi-static reversed-cyclic test method. International Organization for Standardization, Geneva 